\title{
LA VOLUNTAD DE AZORÍN: SCHOPENHAUER BAJO PRUEBA
}

\author{
Roberta JOHNSON \\ University of Kansas
}

Varios estudiosos de Azorín han notado la presencia de Schopenhauer en la obra del escritor monovero, sobre todo en la novela de título schopenhaueriano La voluntad. Por ejemplo, en la "Introducción" a su edición de esta novela, dice E. Inman Fox: "Acaba victoriosa la Voluntad de Schopenhauer, esta fuerza negra sustancia del universo, que juega inconscientemente con la vida humana, sobre la Voluntad de Nietzsche, la afirmación de la personalidad" (1968, pág. 35). Anna Krause identifica el personaje de Yuste específicamente con la filosofía de Schopenhauer: "En un ángulo, casi perdidos en la sombra, tres gruesos volúmenes, que resaltan las azuladas manchas, llevan en el lomo: Schopenhauer...' Él [Yuste] está de acuerdo con Schopenhauer en considerar la existencia como un mal, sufriendo el ser una inevitable parte de la humanidad, y conceptúa el pesimismo 'la actitud más profunda y sabia hacia la vida" (1955, págs. 101-101)'. Leon Livingstone asevera que el título mismo de La voluntad identifica la posición del autor frente a lo que él denomina el tema central de la novela -la relación de la inteligencia y la voluntad, de la contemplación y la acción: "El propio título de esta novela identifica la postura del autor. Se deriva directamente del voluntarismo

\footnotetext{
1 Priscilla Pearsall le proporciona a Yuste el papel de educador de Antonio Azorín en el sentido de lo que era Schopenhauer para Nietzsche (1982). Si la pareja Yuste-Antonio Azorín está basada en "Schopenhauer como educador" de Nietzsche, la inspiración fue probablemente el libro de Lichtenberger sobre Nietzsche y no el ensayo original que es poco probable que Martinez Ruiz hubiera leído en 1901. Lichtenberger señala que Nietzsche escribió sobre Schopenhauer como mentor algún tiempo después de haberse separado de las ideas del maestro. Escribió específicamente sobre una fase que había pasado, lo cual es precisamente la actitud de Antonio hacia su maestro en la segunda y tercera parte de La voluntad.
} 
pesimista de Schopenhauer, para quien la existencia es la expresión de una fuerza de voluntad ciega que es también una fuerza para el sufrimiento y para el mal"(1970, pág. 147$)^{2}$

Ha habido una tendencia en los estudios que han tocado el tema de Azorín y Schopenhauer (al igual que los que tratan a Azorín y su interés por cualquier filósofo) de tomar lo que representa o dice un personaje de su novela La voluntad (sobre todo Yuste y Antonio Azorín ${ }^{3}$ ) como lo que creía Azorín. El presente estudio, sirviéndose de la teoría del dialogismo de la novela que ha propuesto Mikhail Bakhtin, pretende demostrar que Azorín empleó la forma novelística en 1902 para cuestionar varias filosofías (incluso la de Schopenhauer) que tenían vigencia en España a fines del siglo pasado, más bien que para probar la veracidad de una u otra. De hecho, Azorín se sirvió de la ironía inherente en la novela para parodiar ciertas posturas filosóficas. En primer lugar, repaso las anotaciones que hizo Azorín en los libros de Schopenhauer que se encuentran en sus bibliotecas; luego analizo detenidamente algunas de las técnicas narrativas de Azorín en su novela "schopenhaueriana" La voluntad para ver que su uso de Schopenhauer en esta novela no es tan sencillo como se ha indicado en el pasado y que de hecho está contraponiendo las ideas de Schopenhauer a las de otros filósofos como Kant, Nietszche, Taine, y los positivistas (entre los cuales incluyo los evolucionistas) sin optar definitivamente por ninguna.

La biblioteca particular de Azorín que se encuentra en la Casa-Museo Azorín en Monóvar contiene los siguientes títulos que revelan que nuestro escritor lcyó a Schopenhauer en varias etapas de su carrera y que se interesó tanto por las idcas tradicionalmente asociadas con Schopenhauer como por otras más secundarias: Critique de la philosophie kantienne (tr. Cantacuzene. Bucarest: Sotschek, 1889); Parerga y paralipomena. Aforismos sobre la sabiduria en la vida 2 ts. (Madrid: Sociedad General Española de Libreros, s.a.); Pensées \& Fragments (tr. J. Bourdeau. $3^{\mathrm{a}}$ ed. París: Bailliere, 1881); Philosophie et philosophes (tr. Auguste Dietrich. París: Félix Alcan, 1907); y Sobre la voluntad en la naturaleza (tr. Miguel de Unamuno. Madrid: Rodríguez Serra, 1900). La biblioteca familiar que también se encuentra en la Casa-Museo contiene cuatro títulos: Apuntes para la historia de la filosofía (Madrid: Vda. de Rodríguez Serra, s.a.); Metafisica de lo bello y estética (Madrid: B. Rodríguez Serra, s.a.); Parerga y paralipomena 2 ts. (Madrid:

2 El mismo investigador sigue en la misma vena en otro lugar: "The particular irony of the title is not lost on the reader of this confession of moral and spiritual bankruptcy, for the cosmic will serves only to destroy the intelligence, that 'tan bella inteligencia' of the protagonist which disintegrates completely under the stress of disillusionment" (1967, pág. 84). Myrna Solotorevsky (1963) compara las dos novelas en cuanto a su tratamiento del tema de la voluntad y la razón. Asevera que Baroja aspira a la total dominación de la voluntad, mientras que Azorín favorece un equilibrio entre la voluntad y la razón.

Anna Krause (1955, págs. 195-203) asocia a Yuste con José Martínez Ruiz, mientras que Inman Fox (1968, págs. 38-39) asevera que Antonio Azorín es Martínez Ruiz. 
Biblioteca Económico-Filosófica, 1889); y Sur la Religion (París: Félix Alcan, 1906).

Conviene hacer varias observaciones acerca de esta apreciable colección de libros de Schopenhauer que pertenecen a las bibliotecas que poseyó Azorín. Como en el caso de la lectura por Azorín de la filosofía en general, hay una tendencia a concentrarse en las obras de aforismos, más bien que en los tomos que elaboran una filosofía sostenida. Sorprende la ausencia de El mundo como voluntad y representación, obra que por los comentarios de los críticos de Azorín se supondría central en su conocimiento de Schopenhauer ${ }^{4}$. Igual que en los libros de otros filósofos tradicionales (Descartes, Kant, etc.), Azorín hizo pocas anotaciones en las obras schopenhauerianas. En cuanto a las anotaciones en los tomos de Schopenhauer que pertenecen a la biblioteca particular, no suman más de tres o cuatro en cada libro, y a veces no son pasajes que tengan que ver directamente con los conceptos filosóficos centrales de la obra (hay algunas razones para creer que estas obras se leyeron ya en la madurez del escritor). Por ejemplo en el segundo tomo de Parerga y paralipomena encontramos señalado un pasaje sobre "noche" en la página 51 y otro sobre "la vejez" en la página 131 donde hay una raya en el margen al lado del siguiente pasaje: "La mayor energía y la más alta tensión de las fuerzas intelectuales, se manifiestan indudablemente durante la juventud y hasta los treinta y cinco años, o más tarde... " La vejez es un tema que le llamaba la atención a Azorín en numerosos libros suyos, sobre todo al pasar la frontera de los 40 años. Lo más probable es que a la hora de escribir La voluntad manejaba la edición de Parerga y parlipomena que contenía la biblioteca familiar".

En Philosophie et philosophes, señaló tres pasajes que tocan el tema de la barba (p. 84), la época (p. 85), y la lectura (p. 203). En el pasaje sobre la barba que marcó Azorín, Schopenhauer indica que, aunque la barba es natural, debe ser afeitada en los hombres civilizados puesto que lleva una connotación de ferocidad. Sobre el tema de "la época" Schopenhauer apunta la poderosa influencia que tiene en lo que llama "la nourriture intellectuelle" de la época: "Elle repose sur le fait que cette nourriture determine aussi bien la matière que la forme de la pensée." El que se interesara Azorín por un pasaje sobre la lectura no debe sorprendernos ya que nuestro escritor era uno de los más asiduos lectores de entre los intelectuales

- Ver sobre todo Anna Kause (1955, págs. 78-79, 80, 135, 147 y 177), que cita extensamente The World as Will and idea. El hecho de que el tomo no se encuentre en la biblioteca no es una prueba definitiva de que no lo hubiera leído. Pero vale la pena destacar que Azorín no solía prestar libros y que los guardaba muy cuidadosamente; así la ausencia de este tomo tan importante tiene alguna significaciơn.

Ver Roberta Johnson (1996, págs. 11-15), para una explicación de cómo Azorín se servía de la biblioteca familiar en Monóvar a lo largo de su vida. Según Inman Fox (1968, pág. 19), la primera mención que hace Azorín de Schopenhauer es en Soledades, de 1898. Por su parte, Anna Krause (1955, págs. 78-79) indica que cl seudónimo Ahrimán que utilizó Martínez Ruiz en 1890 viene de El mundo como voluntad y representación. 
españoles del siglo veinte y escribía sobre el tema con gran perspicacia. Las frases subrayadas en el pasaje siguiente llevan una raya en la margen: "Au fond, c'est comme avec la lecture: que de fois se regrette-t-on pas de retenir à peine dans sa mémoire la millième partie de ce qu'on lit! Mais ce qu'il y a de consolant dans les deux cas, c'est que ce qu'on a vu, comme ce qu'on a lu, produit son impression sur l'esprit, avant qu'on l'ait oublié, forme celui-ci et le nourrit en réalité; tandis que se qui ne reste que dans la mémoire le bourre et le gonfle seulement, remplit son vide avec une matière qui lui et eternellement etrangère, mais n'apporte rien a son essence." Hasta aquí se ve un interés por temas dispersos más bien que por seguir de cerca el pensamiento del filósofo pesimista, y se sospecha que, como ocurrió con muchas lecturas a lo largo de su carrera periodística, estos intereses se relacionaban con temas de algún artículo que estaba escribiendo en el momento.

En Sobre la voluntad en la naturaleza sí demuestra un interés por unas ideas filosóficas que luego entrarán en su novela "schopenhaueriana" La voluntad. Es muy probable que leyera esta obra más tempranamente que otras y quizás muy cerca de la fecha en que se publicó la traducción española (1900) hecha por Miguel de Unamuno a quien Azorín había conocido durante sus breves estudios en Salamanca. En primer lugar, le interesan a Azorín tres pasajes que tienen que ver con la naturaleza del mundo no humano (este interés se manifestará en La voluntad en algunos pasajes en que Yuste o Azorín discurre sobre la naturaleza como entidad con su propia filosofía, pero como veremos, de una manera irónica) ${ }^{6}$. Un pasaje que recibe la calificación de "fundamental" en la anotación de Azorín es la frase que contiene la idea central de Sobre la voluntad en la naturaleza y que es quizás la idea más importante que se somete a un examen irónico o dialógico en La voluntad: "El rasgo fundamental de mi doctrina, lo que la coloca en contraposición con todas las que han existido, es la total separación que establece entre la voluntad y la inteligencia, entidades que han considerado los filósofos, todos mis predecesores, como inseparables y hasta como condicionada la voluntad por el conocimiento, que es para ellos el fondo de nuestro ser espiritual, y cual una mera función, por lo tanto, la voluntad del conocimiento" (75).

En los libros de Schopenhauer de la biblioteca familiar encontramos otros pasajes señalados que dan más pistas al interés de Azorín por su filosofía tal y como se manifiesta en La voluntad. Típicamente, es el libro más aforístico que contiene el mayor número de anotaciones. Las más importantes de éstas para la temática de La voluntad se refieren a la soledad y la problemática del hombre que tiene que depender de otros. En el primer tomo de Parerga y paralipomena Azorín señala un pasaje de la página 41 que revela un profundo escepticismo sobre las

6. Los pasajes que marcó Martínez Ruiz en Sobre la voluntad en la naturaleza se encuentran en la pág. 147 donde se discute la fisiología vegetal; en la pág. 175, donde se estudia a aplicación del término "quiere" a fenómenos inanimados como "quiere llover" o "quiere salir el sol", y en la pág. 192, donde se discute el misterio o la presciencia del futuro. 
posibilidades de una vida social: "Porque no debemos en manera alguna, esperar gran cosa de otro y del exterior en general. Lo que un individuo puede ser para otro, es cosa muy limitada jcada cual acaba por quedar solo!" En la página 91 Azorín marcó otro pasaje con un mensaje semejante: "Vista la impudencia y la estúpida arrogancia de la mayor parte de los hombres todo aquél que posee méritos cualesquiera, hacía muy bien en hacerlos él mismo ostensibles, para no dejarles caer en un olvido completo..." En el segundo tomo de esta edición encontramos la cantidad más numerosa de indicaciones de Azorín en un libro de Schopenhauer; la mayor parte de estos pasajes también tienen que ver con la soledad: "No se puede ser verdaderamente sui juris, sino cuando se está solo" (p. 33) y "En tesis general sólo consigo mismo se puede estar al unísono perfecto; no se puede estarlo con un amigo, ni con la mujer amada porque las diferencias de la individualidad y del carácter producen siempre una disonancia, por débil que sea ..." (p. 36). En la página 88 señala (con el mismo lápiz rojo que usaba para señalar pasajes en un documento sobre la construcción de la iglesia nueva en Yecla utilizado en el "Prólogo" de La voluntad) un pasaje en que se elogia al hombre contemplativo; en la página 89 un pasaje sobre el amor; en la página 117 un pasaje sobre la futilidad de intentar cambiar de idea a otra persona; y en la página 119 una admonición de guardar el conocimiento para uno mismo. También de forma aforística Metafísica de lo bello y estética (publicado por 1901) lleva significantes subrayados, pero como éstos tienen que ver con la teoría estética de Azorín que voy a tocar al final de este ensayo, los dejo para luego.

Para entender la incorporación que efectúa Azorín de las ideas de Schopenhauer a La voluntad hace falta esbozar brevemente la historia de ideas en España a fines del siglo pasado. La recepción de las ideas de Schopenhauer, sobre todo su noción de la voluntad como una fuerza que existe fuera del pensamiento y que se contrapone al mundo en su representación como idea en la mente se produjo en España entre un torbellino de otras ideas que producían un escenario ideológico bastante conflictivo. Comparada con el resto de Europa, la historia de las idcas en España ha seguido un camino singular. Cuando, en los siglos dieciséis y diecisiete, Bacon redirigía la Europa de la Reforma hacia una aproximación secular, inductiva y científica al conocimiento, y Descartes estaba lanzando su proyección revolucionaria del ego racional como la prueba fundamental de su propia existencia y la de Dios, la España de la Contrarreforma se atrincheró firmemente en su escolasticismo católico, quedándose fuera de la tradición intelectual europea durante dos siglos.

Hasta alrededor de 1860, poco antes de nacer Azorín y los otros miembros de su generación, no tuvo lugar una modernización genuina de la vida intelectual española. En este momento España experimentó la anomalía de la llegada de la tradición racionalista alemana (en forma del krausismo) sólo una década antes de la aparición (gracias a la revolución liberal del 1868) de las diversas manifestaciones del materialismo y del positivismo representadas en el socialismo, el anarquis- 
mo, el marxismo y la teoría de la evolución. A primera vista estas dos orientaciones filosóficas tan diferentes parecen tener mucho en común—un lado pragmático con la meta específica de reformar la sociedad moderna según el modelo utópicopero la base no puede ser más diferente. La total asimilación de las distintas fases del racionalismo desde Descartes hasta Kant, Schopenhauer y Hegel que preparó al resto de Europa para un verdadero debate filosófico sobre los méritos de las teorías sociales no tuvo lugar en España. Las dos orientaciones simplemente chocaron frontalmente durante un período de unos veinte años. Este choque se refleja, quizás mejor que en ningún otro sitio, en la novela de principios de siglo ${ }^{7}$.

Azorín (igual que sus contemporáneos Unamuno y Baroja) inventó un modo novelístico en el que es más relevante el propósito filosófico que en la novela tradicional. En su versión de la novela filosófica, las ideas se hacen evidentes al lector de un modo inmediato más que de un modo latente. Los personajes, más que vivir inmersos en problemas de amor (como la Regenta) o en la lucha por la supervivencia (como Lazarillo de Tormes), piensan y hablan de la vida de forma abstracta. La Regenta mantiene su cualidad representativa hasta el final, mientras que en La voluntad, más filosófica, la dimensión representacional a menudo da pic a una cualidad discursiva más apropiada para el ensayo.

Por supuesto, al introducir este discurso en una novela, le da a ésta cualidades que el discurso filosófico habitual no posee. El artículo periodístico, el ensayo y el tratado filosófico se identifican con la propia voz personal del autor, mientras que en la novela ninguna de las voces - tanto la primera o tercera persona narrativa como las voces de los personajes en diálogo o monólogo interior - se pueden atribuir directamente al autor. Tzvetan Todorov (1971, pág. 27) llama a la literatura narrativa "mediatizada", o "lenguaje no inmediato"; el "yo" de ficción no es el "yo" discursivo. Mikhail Bakhtin (1981, pág. 99) tomó prestada de la física una analogía para iluminar la naturaleza dialógica de la novela, diciendo que la voz del autor se filtra a través de las múltiples voces del discurso narrativo; el autor de una novela es un ventrílocuo.

Así como el personaje Antonio Azorín de José Martínez Ruiz, cl autor de una novela puede ser al mismo tiempo "místico, anarquista, irónico, dogmático, admirador de Schopenhauer, partidario de Nietzsche"(1968, pág. 267), encontrando gestos tentadores y sugerentes o efectos negativos en cada postura sin subscribirse a ninguna. La novela le ofreció a Martínez Ruiz una oportunidad para explorar una variedad de ideas sin adquirir ningún tipo de compromiso con una postura filosófica. La ficción le permitió la libertad que no ofrecía un discurso no ficticio para distanciarse de una postura ideológica específica, así como de sus predecesores y de los contemporáneos que la subscribían. El formato novelístico le permitió con-

7 Para una visión más completa de este fenómeno, ver mi libro (Johnson 1993). 
siderar la validez de posiciones diferentes sin que ello pareciera incoherente o absurdo. El método del tratado filosófico tradicional es el refutar o corregir posturas existentes, forzando un juicio disyuntivo de alternativas. Dos o más posturas filosóficas pueden existir conjuntamente en una sola novela, y novelas con diferentes posturas filosóficas pueden existir sin cancelarse la una a la otra. La naturaleza dialógica de la novcla elucidada por Bakhtin no sólo permite, sino que alienta esta multiplicidad.

Una de las características dialógicas más importantes de la novela es el diálogo en el que las voces de personajes con diferentes puntos de vista se enfrentan y se contradicen unas a otras. De entre las novelas filosóficas de principios de siglo, La voluntad contiene menos diálogo que otras, pero se sirve José Martínez Ruiz de discursos individuales que, al encontrarse yuxtapuestos en pasajes paralelos, tienen la misma función de dejar intactas varias posiciones filosóficas sin darle a ninguna una situación privilegiada. Entran en juego en La voluntad, al lado de ideas de Schopenhauer sobre la voluntad y la inteligencia, el idealismo de Francisco Pi y Margall, el determinismo ambiental de Hyppolite Taine y la ideología anarquista de Kropotkin. También contribuyó a las conflictivas fuentes que crearon $L a$ voluntad $\mathrm{cl}$ interés de Martínez Ruiz por la noción de la voluntad de Nietzsche. Mientras la afirmación de Nietzsche que la voluntad individual de poder contradecía al determinismo ambiental, la noción del eterno retorno, que tanto fascinaba a Martínez Ruiz y más adelante a Azorín, refuerza una visión del mundo que tiene limitadas posibilidades para un cambio y renovación genuinos. Más que proyectar una posición filosófica específica en estas cuestiones, La voluntad ordena gran variedad de técnicas narrativas para poner bajo prueba ideas diversas y enfrentarlas entre sí. Esta práctica recuerda un pasaje que Martínez Ruiz marcó en su copia de La Morale, l'art et la religion d'après Guayau de Alfred Fouillée (1897): “Nous ne savons pas si le fond de la vie est volunté, s'il est idée, s'il est sensation, quoique avec la sensation nous approchions sans doute d'avantage du point central; il nous semble seulement probable que la conscience, qui est tout pour nous, doit etre encore quelque chose le dernier des êtres, et qu'il n'y a pas dans l'univers d'être pour ainsi dire entièrement abstrait de soi" (el subrayado es de Martínez Ruiz).

La yuxtaposición (parataxis) más que la continuidad (hipotaxis) es el recurso estructural primario de Martínez Ruiz en La voluntad. El conflicto entre el dogma de la Iglesia y la filosofía moderna (la de Kant y de Schopenhauer sobre todo) emerge en bloques de texto yuxtapuestos. Los novios Justina y Antonio Azorín son introducidos en capítulos separados en los que cada uno escucha el monólogo de otro personaje (Justina escucha al cura Puche, y Antonio al intelectual Yuste, el personaje más frecuentemente asociado con las ideas de Schopenhauer). Puche da un discurso personal, repleto de numerosas citas bíblicas, a la pasiva Justina, y en el capítulo siguiente Yuste expone ideas tomadas de Kant, Schopenhauer y Nietzsche ante el silencioso Antonio. Estas ideas adquiridas son los formadores primarios de 
los personajes y de sus vidas. Dominada por el catolicismo conservador de su tío, Justina rompe su compromiso con el libre-pensador Antonio y muere en un convento después de una serie de experiencias místicas. Antonio vive por un tiempo según el ideal intelectual de Schopenhauer que ha adquirido en compañía de Yuste, pero finalmente se subordina a una mujer fuerte cuya voluntad dominante tiene tonos nietzscheanos. Alternando las situaciones de Justina y Antonio en capítulos contiguos (pero temporalmente simultáneos), Martínez Ruiz postula la poca conveniencia de la solución de ambos, así como lo inadecuado de los textos y las ideas que los informan.

Los personajes de Martínez Ruiz están atrapados en la telaraña existencial de una transformación continua, hecha y deshecha por las palabras que leen y escuchan. Una yuxtaposición paradigmática textual, más que una elaboración narrativa, revela la elección poco exitosa de la vida religiosa por parte de Justina y finalmente la desilusión progresiva con el intelectualismo schopenhaueriano por parte de Antonio. El fracaso de Justina inicialmente hace que la imitación de Antonio de la vida intelectual parezca el camino más apropiado. A primera vista, Yuste parece ser un modelo moderno más viable que el cura Puche. Una visión más atenta a la yuxtaposición de ideas en los capítulos contiguos y a la voz del narrador omnisciente, que introduce e interrumpe los monólogos de Yuste, ofrece una devaluación del "schopenhaueriano" Yuste como pensador. Con este propósito Martínez Ruiz toma ciertos recursos narrativos del siglo XIX que tan hábilmente manejó Clarín, pero en vez de tejer una narración coherente con ellos, Martínez Ruiz utiliza los recursos intermitentemente, selectivamente e inevitablemente para ridiculizar la autoridad de un personaje, con más frecuencia la de Yuste. La relación entre Yuste y Antonio refleja muchos aspectos de la ambivalente relación de Martínez Ruiz con escritores mayores como Pi y Margall y Clarín. Sentía repugnancia por las figuras autoritarias, pero encontraba necesario cultivar su amistad para conseguir el éxito literario que buscaba.

Félix Martínez Bonati y John Searle (1981) distinguen entre "actos miméticos" o "actos ilocucionarios pretendidos" y otros tipos de afirmaciones pronunciadas por los narradores ${ }^{8}$. Las oraciones miméticas que no contienen elementos de opinión o juicio establecen el mundo ficticio, los cimientos primarios de verdad indiscutible dentro del contexto de la novela. Tal es la primera oración del capítulo 4 de La voluntad: "A lo lejos, en el fondo, sobre un suave altozano, la diminuta iglesia de Santa Bárbara se yergue en el azul intenso" (75). Martínez Ruiz empleó estas afirmaciones puramente miméticas representacionales (igual que Clarín) para presentar una situación en la que las palabras del propio personaje parecen ser menos

$8 \quad$ Thomas Pavel (1983) discute la distinción que hace John Searle entre los actos ilocucionarios pretendidos y las aseveraciones propias del narrador (como la frase de Tolstoi: "Todas las familias felices son felices de la misma manera") que no pertenecen a la historia ficticia. Parece evidente que Martínez Bonati y Searle están pensando en la misma categoría general de frases. 
verídicas, para así, de un modo latente, exponer la hipocresía de un personaje ${ }^{9}$. Por ejemplo, después de que Yuste invoca autoritariamente el darwinismo social y la unidad del mundo físico y moral para negar el concepto de la propiedad privada, el narrador nos informa que Yuste ha acabado de leer un artículo que omite su nombre de entre los ilustres asociados de un famoso político a quien él considera un amigo.

Así el narrador revela que el apasionado discurso de Yuste es el producto de un ego abatido más que de una firme convicción. Más tarde, Yuste, cuya actitud ha mejorado, revierte su posición radical anterior, ante la sorpresa y consternación de Azorín, quien ha llegado preparado para apoyar la posición del maestro. El maestro ahora cita pasajes de Platón y Tolstoy para dar cuerpo a su nueva posición más moderada y conciliatoria, indicando que los textos pueden ser ordenados para formular cualquier verdad. El narrador da abundante evidencia de que Yuste es un pensador que está con frecuencia preocupado más por el virtuosismo de su expresión que por la consistencia de su posición ideológica. Más que la voz schopenhaucriana de Martínez Ruiz, Yuste representa un problemático modelo intelectual y las tensiones que inevitablemente existen entre mentores y discípulos.

Además de las afirmaciones miméticas, Martínez Ruiz ocasionalmente utiliza el estilo indirecto libre, pero a diferencia del narrador de Clarín que se insinúa en las consciencias de los personajes con un liberal abandono, el narrador de Martínez Ruiz coincide muy raramente con el discurso de un personaje y, cuando lo hace, es para obtener un efecto muy estudiado, principalmente para cuestionar la credibilidad de otro personaje. Yuste es el objeto de este tratamiento en varias ocasiones, poniendo en cuestión su oscilante postura intelectual e introduciendo un antagonismo sutil entre él y su discípulo Azorín. Antonio Azorín no es un seguidor tan fiel de Yuste como con frecuencia se ha supuesto. El método indirecto libre de revelar su antagonismo permite a Antonio mantenerse en apariencia como un devoto admirador de su mentor (postura que otros investigadores han tomado al pie de la letra). Por ejemplo, cuando el narrador nos dice que "el maestro, calmado con la apacibilidad de la noche, sonrió, satisfecho de su pintoresca asociación de ideas, y le pareció que sus paradojas de hombre sincero valían más que las actas de diputado y las carteras ministeriales de su frívolo amigo" (84), adopta la perspectiva de Antonio que ha sido testigo de esta "pintoresca asociación".

Después de una serie de pasajes en los que Yuste expone elocuentemente la futilidad de la metafísica, la eternidad contra la temporalidad, y el darwinismo social, el capítulo siguiente empieza con esta observación del narrador: "Este buen maestro - - ihabrá que confesarlo!- - es en el fondo un burgués redomado" (98). La palabra "maestro" y el sentimiento de culpa implicado en "confesarlo" asocia esta opinión de Yuste más con su discípulo Antonio que con el observador objetivo.

9 Ver Martínez Bonati (1981, pág. 30) para una discusión de la manera en que el discurso de los personajes contrasta con el del narrador. 
En algunas ocasiones, el narrador atribuye directamente a Antonio pensamientos sobre la naturaleza quijotesca de Yuste: "En tanto, Antonio piensa en que este buen maestro, a través de sus cóleras, de sus sonrisas y de sus ironías, es un hombre ingenuo y generoso, merecedor a un mismo tiempo - como Alonso Quijano el Bueno-_e admiración, de risa y de piedad" (113). La ambivalencia que el propio Martínez Ruiz sentía hacia las figuras autoritarias paternalistas como Clarín queda incluida con gran maestría en estos fugaces momentos narrativos.

Yuste, el supuesto schopenhaueriano, en muchos pasajes suena mucho más a Kant, a quien Schopenhauer modificaba muy estudiosamente. Yuste enfatiza que todas las cosas pasan, evocando así el principio kantiano de que las sensaciones son sólo manifestaciones de la substancia y que "La imagen lo es todo". Tanto la frase "todo pasa" y "la imagen lo es todo" son estribillos comunes a lo largo de toda la novela en contextos que hacen a estas ideas parecer cada vez más absurdas. Cuando Yuste se muere al final de la primera parte, sus últimas palabras revelan que no puede confirmar nada, y la sección termina con un borracho Antonio que repite el estribillo del maestro, "La imagen lo es todo". Esta frase se repite a menudo en la segunda parte de la novela bajo circunstancias parecidas. Por ejemplo, un Antonio ebrio grita, para gran asombro de algunos camareros del café: "Hay que romper la vieja tabla de valores morales, como decía Nietzsche... ¡Viva la imagen!" (215). En el capítulo 5, los intereses de Yuste se vuelven hacia temas más materialistas. Ahora es un determinista confirmado. La propiedad privada es el gran mal; si el medio no cambia, la humanidad no puede cambiar. El mundo físico y moral se gobiernan por las mismas leyes (esto después de haber abrazado un idealismo estricto en el discurso previo).

Una confusión incluso mayor se da en el siguiente capítulo, donde Yuste intenta combinar su deseo de cambio con su deseo de algún tipo de continuidad eterna, una nostalgia del pasado tradicional de España. El dilema se produce literalmente en la descripción del árbol bajo el que se sientan Yuste y Antonio. Un árbol místico les da sombra mientras discuten el cambio político e inventan una alegoría de tres hombres que consultan a sus mayores sobre un plan de reforma. Un personaje que representa a $\mathrm{Pi}$ y Margall está trabajando en generalidades abstractas, mientras que Salmerón quiere preservar derechos específicos. Cuando los reformistas confrontan todas las cuestiones abstractas y específicas de sus mentores, su plan queda reducido a la nada y concluyen con una ironía basada en la idea del Pangloss voltairiano que el mundo presente es el mejor de los mundos posibles. El estribillo que dice que todo debe cambiar es evocado de nuevo, seguido de la afirmación de que el misticismo y la tradición representan lo mejor de España. La metafísica es una fantasía humana, un juguete con el que juegan los hombres. El capítulo concluye con una historia en la que un filósofo kantiano y un empresario de carnaval se ponen de acuerdo en que no podemos conocer los "noumenos", que sólo los "fenómenos" son reales. 
Entretejidas con los capítulos que indican el progreso de Justina en su camino de perfección están las visitas al padre Lasalde, un hombre de fe sencilla y envidiable, y capítulos sobre los fracasados experimentos de Quijano para diseñar un cohete y un torpedo. Yuste empieza a aceptar la fe del cura Lasalde cuando éste responde a su lema "Todo es lo mismo y todo cambia" con la observación de que Dios es permanente. Finalmente, la filosofía se reduce a la naturaleza. En una excursión campestre, Antonio y Yuste ven un "escarabajo filosófico" que ha leído la Crítica de la Razón Pura; es un "filósofo perfecto", dice Yuste: " $¡$ cuántas cosas me diría que no me dice Platón en sus Diálogos, ni Montaigne, ni Schopenhauer!" (160). En la segunda parte Antonio continúa la metáfora de la "filosofía como naturaleza", aunque quizá incluso de manera más peyorativa; afirma que un perro en el bar donde está bebiendo es más sabio que Aristóteles, Spinoza y Kant juntos.

Ahora Antonio sigue los pasos de Yuste, y alterna el idealismo con el materialismo, y, como su mentor, intenta combinar ambos. En el quinto capítulo de la segunda parte, se proclama como un determinista convencido, y dice que "todo es necesario y fatal" (218), pero justo en la página siguiente dice " El mundo es una inmensa litografía de Daumier!" (219). Antonio no puede aceptar los pronunciamientos de Yuste sobre el eterno retorno; estas teorías, dice, ya fueron promulgadas por Toland y Lucrecio. Los compañeros filosóficos que elige en Madrid para recmplazar a Yuste no proporcionan más luz sobre la naturaleza de la vida y del mundo. Visita a Pi y Margall; la charla que tienen se vuelve hacia el positivismo de Comte, pero de regreso a casa llega a la conclusión de que todo el filosofar de Pi no ha conducido a nada. Una visita a Olaiz (Baroja) confirma estos sentimientos, ya que Olaiz cree que la revolución y la democracia son errores y que el socialismo se está desmoronando; el futuro, según Olaiz, reside en el individuo.

En la tercera parte, la técnica de yuxtaposición cesa repentinamente cuando Antonio decide abandonar Madrid y la vida intelectual para buscar la "vida real". Al igual que el protagonista de Diario de un enfermo, concluye que los libros no enseñan nada que no sea ya evidente en la vida: "En filosofía, desde Aristóteles hasta Kant, ¿quién ha dicho nada nuevo?" (Azorín 1947, pág. 262). Al igual que Yuste gravitaba hacia la fe del padre Lasalde, por un tiempo Antonio encuentra solaz en la lectura de libros religiosos en un monasterio donde ha parado para descansar. Aquí resume toda su postura filosófica incluyendo absolutamente todo lo que ha leído: misticismo, anarquismo, ironía, dogmatismo, Schopenhauer y Nietzsche. Finalmente decide que la sobreintelectualización ha paralizado su voluntad, una situación que intenta remediar volviendo a su pueblo y casándose con su opuesto, la voluntariosa y dominante Iluminada.

Antonio rechaza definitivamente a Yuste y sus ideas al repudiar el estilo de vida intelectual yustiano y al elegir vivir como un caballero de casino en una ciudad pequeña, conocido por los lugareños como Antoñico. Durante más de diez años Antonio ha seguido los pasos de Yuste como estudioso de Kant, Schopenhauer 
y Nietzsche, y sus carreras han sido asombrosamente similares. Pero Antonio supera a Yuste, quien en su lecho de muerte reniega de toda la tradición intelectual europea con un gesto: "no puedo afirmar nada sobre la realidad del universo... La inmanencia o trascendencia de la causa primera, el movimiento, la forma de los seres, el origen de la vida... Arcanos impenetrables... eternos..." (179). Antonio no espera a la muerte para revelar su desdén por el intelectualismo; lo evita al cambiar su postura vital.

Las técnicas narrativas iconoclastas de Martínez Ruiz, que construyen y destruyen simultáneamente posiciones filosóficas, culminan con la inmolación de sus propias ideas. Varios de los discursos de Yuste y Antonio están sacados textualmente de artículos que Martínez Ruiz había publicado bajo su propio nombre. Al asignar sus propias palabras a personajes que han probado ser inconsistentes y poco fiables, Martínez Ruiz borra su propia postura intelectual previa. Un ejemplo específico de este tono autodestructivo ocurre avanzada la novela. Después de que un Antonio muy borracho e incoherente pronuncia las palabras exactas de un artículo de Martínez Ruiz, el narrador comenta que "Verdadcramente, se necesita beber mucho para pensar de este modo" (215).

La voluntad es una obra desafiante que reta cualquier postura filosófica fija. No me parece que haya suficiente evidencia en La voluntad para asegurar que Azorín pensaba de una u otra manera sobre las ideas de Schopenhauer o de Nietzsche en cuanto a la cuestión de la voluntad. Yuxtaponía las dos posturas y nos deja sin conclusión. Esta ambiguedad queda aún más evidente en Antonio Azorín donde la metafísica es destronada mucho menos sutilmente que en la novela de 1902 . No hay ninguna de las largas discusiones sobre temas filosóficos ni inteligentes maniobras narrativas para cuestionar una postura ideológica. El tema de la filosofía sí surge, pero se abandona de una forma rápida y humorística. Schopenhauer se cita como el autor de La voluntad en la naturaleza y como alguien que podría encontrar ameno el hecho de que la espinaca y el perejil no se pueden transplantar. La visión de una araña provoca la pregunta: “¿Es un animal nietzscheano la araña?” (1947, pág. 1019). Sarrió está leyendo el Diccionario general de cocina, que él llama un libro trascendental y filosófico; se refiere a Antonio Azorín como un no-Spinoza, y un obispo que lee todo lo nuevo y que cree que "Nietzsche, Schopenhauer, Stirner... son los bellos libros de caballería de hogaño" (1947, pág. 1091). El obispo continúa diciendo que a la gente joven que sigue a estos pensadores les falta "esa simplicidad, esa visión humilde de las cosas, esa compenetración con la realidad que Alonso Quijano encontró sólo en su lecho de muerte, ya curado de sus fantasías" (1947, pág. 1091).

Es difícil no ver Las confesiones de un pequeño filósofo como la secuela espiritual (si no real) de Antonio Azorín; más que debatir ideas filosóficas, este pequeño filósofo intenta alcanzar una visión humilde de las cosas, y revisa su propia evolución desde la niñez a la edad adulta primero en su región natal y luego en 
Madrid. Ahora ni siquiera presenta ideas metafísicas para ridiculizarlas después: "Yo no quiero hacer vagas filosofías; me repugnan las teorías y las leyes generales, porque sé que circunstancias desconocidas para mí pueden cambiar la faz de las cosas, o que un ingenio más profundo que el mío puede deducir de los pequeños hechos que yo ensamblo leyes y corolarios distintos a los que yo deduzco. Yo no quiero hacer filosofías nebulosas; que vea cada cual en los hechos sus propios pensamientos" (Azorín 1920, pág. 156). Los objetos de atención son pequeñas áreas de la vida - días de colegio, juegos infantiles, comidas, el campo, la apariencia de la gente y su comportamiento- que precede toda genial abstracción filosófica que se formule acerca de ellas. Si el pequeño filósofo evoca el tiempo eterno, no se asocia con Nietzsche sino con un reloj de cuco, "símbolo de lo inexorable y de lo eterno" (138), y si piensa en el Infinito, es al ver a un cierto tipo de mujer o al ver el mar.

Cuando Martínez Ruiz, convertido ya en Azorín, escribió Las confesiones de un pequeño filósofo en 1904, ya había dejado su postura desafiante frente a las filosofías de Schopenhauer, Nietzsche y otros que había retado en La voluntad. Asume lo que será su actitud estética madura que denomina Leon Livingstone "la estética del reposo" (1970, pág. 147) ${ }^{10}$, y Miguel Ángel Lozano "una estética de la resignación" (1996) ${ }^{11}$. En esta nueva postura, como han señalado estos dos investigadores, podemos observar la herencia más permanente que dejó Schopenhauer en la obra de Azorín: una visión del arte como una consolación del sufrimiento que proporciona la vida ${ }^{12}$.

10 Livingstone encuentra esta estética ya en La voluntad: "La ponderación de la contemplación como una fuente positiva de creatividad, base de la anunciada estética del reposo, constituye una revisión de valores que da paso al principio de la supresión de la intriga de la novela. Esta relación es marcada en La voluntad, donde la trama, tratada con verdadero desdén, pues le falta una auténtica estructura, es el vehículo de expresión del problema de la relación entre inteligencia y voluntad, entre contemplación y acción". Pero yo creo que no se inicia de verdad la "estética del reposo" hasta las Confesiones de un pequeño filósofo; la estética de La voluntad es más bien conflictiva.

$"$ En la pág. 112 escribe el citado investigador: "De aquí [de Schopenhauer] procede [...] la concepción [...] del arte como contemplación desinteresada que libera de la tiranía de la voluntad, ejerce un influjo calmante, propicia un conocimiento esencial de los resortes vitales, nos lleva a intuir arquetipos y, por fin, nos conduce a la resignación".

12 Recordemos aquí algunas citas de Metafísica de lo bello y estética de Schopenhauer que señaló Azorín en su ejemplar: "Lo mismo sucede con las vasijas antiguas, cuya belleza resulta de que expresan de una manera tan sencilla lo que está determinado que sean y cumplan” (25). "Un placer musical mucho más puro que la ópera lo proporcionaba la misa cantada, cuyas palabras, generalmente ininteligibles, o los aleluya, gloria, eleison, amen, etc., repetidas hasta loinfinito, se convierten en un sencillo solfeo, en el que la música, conservando sólo el carácter eclasiástico general, se siente libre y no la perjudican en su propio terreno, como en el canto de la ópera" (38). 


\section{REFERENCIAS BIBLIOGRÁFICAS}

AZORÍN. 1947. Obras Completas, vol. I, Madrid, Aguilar.

- 1920. Las confesiones de un pequeño filósofo, Madrid, Caro Raggio.

BAKHTIN, Mikhail. 1981. The Dialogic Imagination, Austin, University of Texas Press.

FOUILÉE, Alfred. 1897. La Morale, l'Art et la Religion d'après Guyau, Paris, Felix Alcan.

FOX, E. Inman. 1968. "Estudio introductorio" a su ed. de J. Martínez Ruiz (Azorín), La voluntad.

JOHNSON, Roberta. 1993. Crossfire: Philosophy and the Novel in Spain 19001934, Lexington, University Press of Kentucky.

KRAUSE, Anna. 1955. Azorín. El pequeño filósofo, Madrid, Espasa-Calpe.

LIVINGSTONE, Leon. 1967. "The Theme of Intelligence and Will in the Novels of Azorín", Romanic Review, núm. 58, págs. 83-94.

- 1970. Tema y forma en las novelas de Azorín, Madrid, Gredos.

LOZANO MARCO, Miguel Ángel. 1996. "Azorín. Una estética de la resignación", en Azorín (1904-1924), Universidades de Murcia y de Pau, págs. 109114.

MARTÍNEZ BONATI, Félix, y John Searle. 1981. Fictive Discourse and the Structure of Literature, Ithaca, Cornell University Press.

MARTÍNEZ RUIZ, J. 1968 [1902]. La voluntad, ed. de E. Inman Fox, Madrid, Castalia.

PAVEL, Thomas. 1983. "The Borders of Fiction", Poetics Today, núm. 4, págs. 8388.

PEARSAL, Priscilla. 1982. "Azorín's La voluntad and Nietzsche's 'Schopenhauer as Educator'”, Romance Notes, vol. 25, núm. 2, págs. 121-126.

SOLOTOREVSKY, Myrna. 1963. "Notas para el estudio intrínseco comparativo de Camino de perfección y La voluntad", Boletín de Filología, núm. 15, págs. 111-164.

TODOROV, Tzvetan. 1971. The Poetics of Prose, Ithaca, Cornell University Press. 